\title{
The Effect of Doctor-Consumer Interaction on Social Media on Consumers' Health Behaviors: Cross-Sectional Study
}

Tailai $\mathrm{Wu}^{1}$, PhD; Zhaohua Deng ${ }^{1}$, PhD; Zhanchun Feng ${ }^{1}$, PhD; Darrell J Gaskin ${ }^{2}$, PhD; Donglan Zhang ${ }^{3}$, PhD; Ruoxi Wang ${ }^{1}, \mathrm{PhD}$

\footnotetext{
${ }^{1}$ School of Medicine and Health Management, Tongji Medical College, Huazhong University of Science and Technology, Wuhan, China

${ }^{2}$ Department of Health Policy and Management, Bloomberg School of Public Health, Johns Hopkins University, Baltimore, MD, United States

${ }^{3}$ Department of Health Policy and Management, College of Public Health, University of Georgia, Athens, GA, United States
}

\section{Corresponding Author:}

Zhanchun Feng, PhD

School of Medicine and Health Management

Tongji Medical College

Huazhong University of Science and Technology

13\# Hangkong Road, Wuhan City, Hubei Province

Wuhan, 430074

China

Phone: 862783692731

Fax: 862783692727

Email: zcfeng@hust.edu.cn

\section{Abstract}

Background: Both doctors and consumers have engaged in using social media for health purposes. Social media has changed traditional one-to-one communication between doctors and patients to many-to-many communication between doctors and consumers. However, little is known about the effect of doctor-consumer interaction on consumers' health behaviors.

Objective: The aim of this study was to investigate how doctor-consumer interaction in social media affects consumers' health behaviors.

Methods: On the basis of professional-client interaction theory and social cognitive theory, we propose that doctor-consumer interaction can be divided into instrumental interaction and affective interaction. These two types of interactions influence consumers' health behaviors through declarative knowledge (DK), self-efficacy (SE), and outcome expectancy (OE). To validate our proposed research model, we employed the survey method and developed corresponding measurement instruments for constructs in our research model. A total of 352 valid answers were collected, and partial least square was performed to analyze the data.

Results: Instrumental doctor-consumer interaction was found to influence consumers' DK $\left(t_{294}=5.763, P<.001\right), \mathrm{SE}\left(t_{294}=4.891\right.$, $P<.001)$, and OE $\left(t_{294}=7.554, P<.001\right)$ significantly, whereas affective doctor-consumer interaction also impacted consumers' $\mathrm{DK}\left(t_{294}=4.025, P<.001\right), \mathrm{SE}\left(t_{294}=4.775, P<.001\right)$, and OE $\left(t_{294}=4.855, P<.001\right)$. Meanwhile, consumers' $\mathrm{DK}\left(t_{294}=3.838, P<.001\right)$, $\mathrm{SE}\left(t_{294}=3.824, P<.001\right)$, and OE $\left(t_{294}=2.985, P<.01\right)$ all significantly affected consumers' health behaviors. Our mediation analysis showed that consumers' DK, SE, and OE partially mediated the effect of instrumental interaction on health behaviors, whereas the three mediators fully mediated the effect of affective interaction on health behaviors.

Conclusions: Compared with many intentional intervention programs, doctor-consumer interaction can be treated as a natural cost-effective intervention to promote consumers' health behaviors. Meanwhile, both instrumental and affective interaction should be highlighted for the best interaction results. DK, SE, and OE are working mechanisms of doctor-consumer interaction.

(J Med Internet Res 2018;20(2):e73) doi: 10.2196/jmir.9003

\section{KEYWORDS}

physician patient relationships; health behavior; social media; social theory; psychological theory; medical informatics 


\section{Introduction}

\section{Background}

Social media is penetrating people's daily life and influencing their health-related activities. Consumers, patients and nonpatients included, are interacting with health professionals or with each other on social media more often than ever before. In the United States, $81 \%$ of adults have social media profiles [1]. In China, the most populous country in the world, the number of social media consumers is estimated to reach 679.19 million by 2021 [2]. A US-based study indicates that nearly one-third of consumers' health-related activities are conducted through social media and almost two-third of consumers search for information regarding a specific doctor or a health professional using social media [3]. Moreover, almost half of consumers claim that information from social media affects their health-related decisions, and more than half of them trust doctors' Web-based posts or blogs [4]. Currently, more than $60 \%$ of doctors use various forms of social media for personal or professional reasons, and this percentage has been increasing in recent years [5]. Both consumers and doctors have engaged in using social media to disseminate health-related information, and therefore, social media could be an important medium for interactions between doctors and consumers.

Social media are Internet-based applications that build on Web 2.0 techniques to allow the creation and exchange of user-generated content. These applications can replace the traditional one-to-one communication with the many-to-many communication paradigm between patients and doctors [6]. However, doctors' behaviors on social media may be different from those in the offline context. It may be challenging to apply principles of medical practice for doctors in the social media setting because social media may make them feel less restrained [7]. Besides, social media empowers consumers by providing them with not only the opportunities to interact with many doctors at the same time but also the access to know other consumers with similar interests or experiences [8]. Moreover, the content of interaction may be different in a social media setting. As doctors cannot provide medical diagnosis or treatment using social media directly, the health problems discussed during the interaction may not be acute and serious, consumers may feel less anxious, and therefore, doctors' affective behaviors may not be as important as they are in the offline context. Hence, the new communication approach, behaviors, and content affect the relationship between consumers and health professionals, which may influence consumers' health outcomes and well-being [9].

Despite the fact that individuals' health outcomes of using social media, including health-related emotions, physical conditions, and beliefs, have been well studied, social media's impact on health behaviors is less understood [10]. Improving health behaviors, such as ceasing smoking, increasing physical activity, keeping a healthy diet, and avoiding overconsumption of alcohol, can substantially lower the risk of dying prematurely [11]. Health behaviors have been found to be correlated with many chronic noninfectious diseases such as diabetes [12], hypertension [13], stroke [14], Alzheimer disease [15], and even cancer [16]. Moreover, unhealthy lifestyle leads to poor health status, obesity [17], depression, anxiety [18], and even poor academic performance [19]. Improving health behaviors at the population level also helps promote health equity in the society [20]. Given the significant impact of health behaviors, policy makers in different countries have taken actions to promote health behaviors. For example, the US Department of Health and Human Services has introduced Healthy People 2020 to promote health behaviors [21]. In the meantime, the State Council of China has set promoting healthy lifestyle among Chinese people as one of the major goals of the Healthy China 2030 Program [22]. Therefore, developing effective interventions to improve health behaviors is very meaningful and contributive. With regard to health behaviors in the social media context, prior literature has shown that several interventions based on social media are effective in changing patients' behaviors and promoting their health status [23-25]. Nevertheless, the effect of interaction between doctors and consumers on social media on consumers' health behaviors has not been studied. Thus, our research question is as follows:

How does doctor-consumer interaction on social media influence consumers' health behaviors?

Overall, we hypothesize that doctor-consumer interaction influences consumers' health behaviors significantly through some potential pathways. Compared with health promotion interventions using traditional approaches, doctor-consumer interaction on social media could be a low-cost health promotion intervention [26]. Therefore, it is worth evaluating the effect of doctor-consumer interaction and identifying the mechanisms of how it works. To address this question, we ground our research on professional-client interaction theory to conceptualize doctor-consumer interaction in the social media context and social cognitive theory to explore the working mechanisms of doctor-consumer interaction.

\section{Theoretical Foundation}

In this study, we integrate professional-client interaction theory and social cognitive theory to help us understand the effect of doctor-consumer interaction on health literacy. Professional-client interaction theory is mainly used to comprehend doctor-consumer interaction because the subtypes of interaction can be used to describe doctor-consumer interaction, whereas social cognitive theory is used to explore the working mechanisms of doctor-consumer interaction in this study because the interaction can be treated as a learning process.

Professional-client interaction theory claims that physicians' behaviors toward patients in physician-patient interaction could be classified as instrumental behaviors and affective behaviors [27]. Instrumental behavior is about the content of physicians' behaviors that focuses on the solution of a health problem, whereas affective behavior is about the mode of physicians' behaviors that requires physicians to treat patients as a person rather than a case [28]. We argue that the categorization of physicians' behaviors toward patients in professional-client interaction can be extended to the social media context as doctors can still solve consumers' health problems and provide emotional support on social media. To contextualize the 
professional-client interaction in the social media context, we divide doctor-consumer interaction into instrumental interaction and affective interaction [29]. On the basis of instrumental behavior, we define instrumental interaction as a doctor-consumer interaction that focuses on the solution of consumers' health concern. Toward affective interaction, we define it as the interaction that cares about consumers' emotions in line with affective behaviors. The effect of instrumental and affective interaction is reasoned and hypothesized in the following sections.

Social cognitive theory, originally labeled as social learning theory, assumes that one learns by observing models' behaviors and performs their behaviors in the social context [30]. Meanwhile, the maintenance of learned behaviors over time depends on self-regulation and reinforcement. Learned behaviors are results of the dynamic reciprocal interaction among personal, behavioral, and environmental determinants. Furthermore, learned behaviors continue to interact with personal and environmental determinants in the reinforcement process, where beneficial behaviors are repeated and others are avoided. The determinants of learned behaviors can be categorized into 5 categories: outcome expectancy (OE), observational learning, environmental factors, self-regulation, and moral disengagement [31]. Besides, among environmental factors, incentive motivation and facilitation are the 2 main factors [32]. Incentive motivation is a reward or punishment from the environment, whereas facilitation is a resource or tool for facilitating behaviors. In our study, through interacting with doctors on social media, consumers' health behaviors can be developed in the interaction process because doctors can be the role model or the information source of healthy lifestyle behaviors. Therefore, doctor-consumer interaction can be treated as a learning process and be understood by social cognitive theory. The determinants of learned behaviors in social cognitive theory could be referred to explore the determinants of health behaviors.

\section{Research Model and Hypotheses}

According to professional-client theory, we divide doctor-consumer interaction into instrumental interaction and affective interaction. Meanwhile, according to social cognitive theory, we propose that the 2 types of interaction influence consumers' health behaviors through declarative knowledge (DK), self-efficacy (SE), and OE. The specific hypothetic relationships are depicted in Figure 1.

\section{Declarative Knowledge, Self-Efficacy, Outcome Expectancy, and Health Behaviors}

According to the content of knowledge, knowledge can be classified as declarative knowledge and procedural knowledge [33]. DK is about facts and things that concern the static properties of objects, persons, or events, whereas procedural knowledge is about dynamic skillful actions. For example, information about attributes, facts, and situations is declarative knowledge, whereas procedures for actions or experience are usually referred to as procedural knowledge. Therefore, DK is easy to be communicated and described by verb, whereas procedural knowledge should be acquired in practice. Because consumers only can learn the procedural knowledge when they practice it, DK is more feasible and suitable in our context. Because DK can help people access to the meaning of health behaviors [34], the meaning of health behaviors influences people's attitudes and their behaviors. Therefore, we can hypothesize the following:

H1: DK positively influences consumers' health behaviors.

SE is people's judgment of their capability to perform a specific behavior or task [30]. It has 3 dimensions: magnitude, strength, and generalizability. Magnitude of SE refers to the degree of difficulty to which people believe they can attain a certain kind of behavior, whereas strength of SE is confidence about the judgment. Generalizability reflects the degree to which the judgment can be generalized to different situations. In our context, SE can be consumers' judgment to master the cognitive and social skills to improve or maintain their health status. As SE can affect people's level of effort and persistence on a specific behavior according to the dimensions of SE [35], high SE may lead people to put in more effort to do the behaviors and insist on them longer. Hence, we can hypothesize the following:

H2: SE positively influences consumers' health behaviors.

Figure 1. Research model.

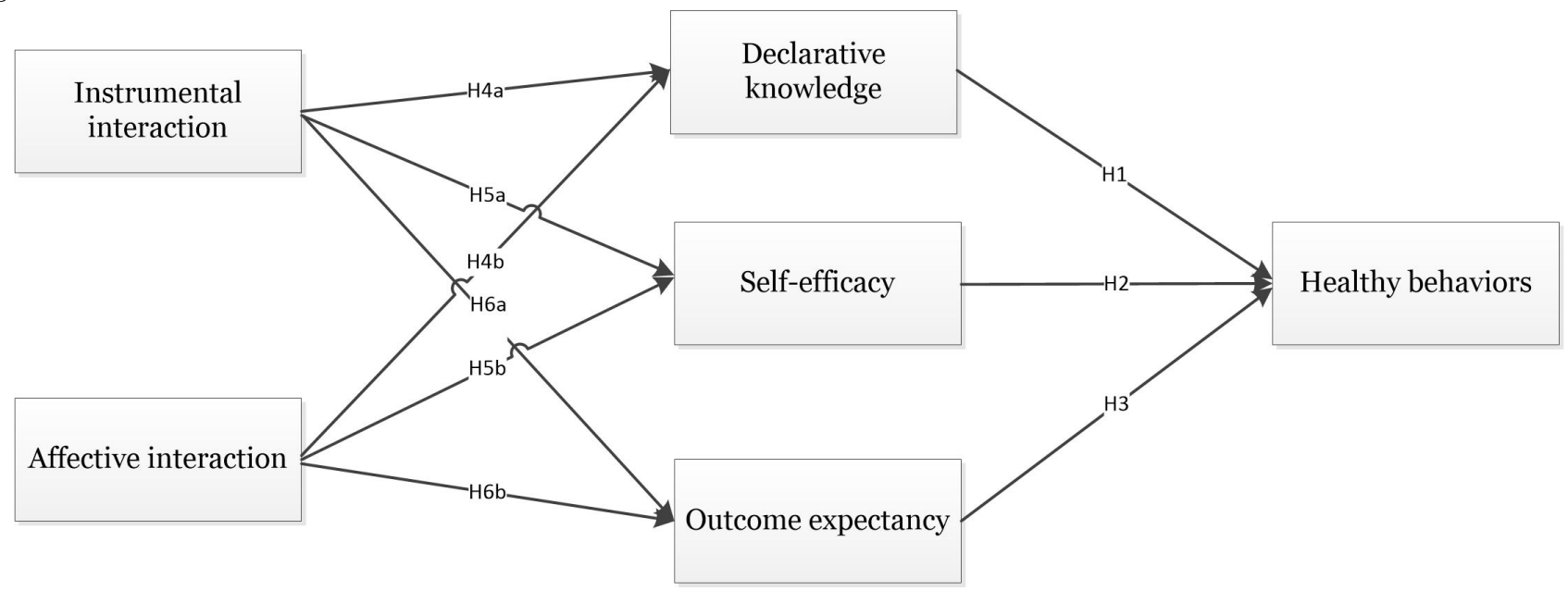


OE refers to the belief that the expected outcomes are resulted in given behaviors [36]. Three forms of OE exist, including physical form, social form, and self-evaluation form. Physical outcomes include positive and negative effects of behaviors, while the given behaviors may also receive social approval and disapproval. Self-evaluation toward the given behaviors may also be positive or negative [37]. Consumers' behaviors are regulated by these different forms according to given behaviors' consequences. In our study, OE is about whether consumers' interaction with doctors on social media can solve their health concerns or problems. Since people are generally rational, their self-interest behaviors can be regulated by the outcomes of behaviors [38]. Positive outcomes may stimulate people to implement the corresponding behaviors. Therefore, we can hypothesize the following:

H3: OE positively influences consumers' health behaviors.

\section{Doctor-Consumer Interaction and Declarative Knowledge}

In doctor-consumer interaction, consumers not only have opportunities to ask more questions to doctors but also have access to health information from other sources. Therefore, the doctor-consumer interaction makes consumers acquire health information that can be processed and authenticated to form health knowledge [39]. Given that consumers who interact with doctors on social media can use only Web-based digital tools including texts, pictures, or videos, they cannot make use of the health information on social media directly. Therefore, doctor-consumer interaction can increase consumers' DK. With regard to 2 types of doctor-consumer interaction, consumers can receive information about their health problems directly in instrumental interaction and get information about dealing with their anxiety in affective interaction [40]. Thus, we can hypothesize the following:

$\mathrm{H} 4 \mathrm{a}$ : Instrumental interaction between consumers and doctors on social media positively influences consumers' DK.

$\mathrm{H} 4 \mathrm{~b}$ : Affective interaction between consumers and doctors on social media positively influences consumers' DK.

\section{Doctor-Consumer Interaction and Self-Efficacy}

Four information cues have been proposed to influence the formation of SE: enactive mastery, vicarious experience, verbal persuasion, and emotional arousal [41]. Enactive mastery is people's performance attainment, whereas vicarious experience is from behavioral models. Verbal persuasion is to make people believe their capability of doing some tasks, whereas emotional arousal is the psychological state that arouses people's capability. In doctor-consumer interaction, doctors can be the behavioral models who give vicarious experience to consumers and may persuade consumers to develop health behaviors. In our study, toward the relationship between doctor-consumer interaction and SE, vicarious experience and verb persuasion can be the mediating processes. Thus, we can hypothesize the following:
H5a: Instrumental interaction between consumers and doctors on social media positively influences consumers' SE.

$\mathrm{H} 5 \mathrm{~b}$ : Affective interaction between consumers and doctors on social media positively influences consumers' SE.

\section{Doctor-Consumer Interaction and Outcome Expectancy}

Consumers' OE can also be affected by vicarious experience [42]. Positive learned experience conveys the possible reward of doing specific behaviors and strengthens one's expectation of positive outcome. In our study, as doctors can be health models and provide support to consumers during the interaction with them, the possibilities of solving consumers' health problems and performing healthy lifestyle behaviors are increased [43]. Meanwhile, interacting with doctors on social media enforces the social ties between consumers and doctors and helps consumers acquire different kinds of social support from doctors. Thus, we can hypothesize the following:

H6a: Instrumental interaction between consumers and doctors on social media positively influences consumers' OE.

H6b: Affective interaction between consumers and doctors on social media positively influences consumers' OE.

\section{Methods}

\section{Data Collection}

Data were collected in China, which has the largest social media market in the world. The Web-based survey was conducted using Zhubajie, which is the biggest crowdsourcing platform in China. Survey announcement was posted in Zhubajie, and registered service providers were invited to fill the questionnaires. In the announcement, we set several requirements to judge whether the answers were qualified. The requirements included using social media, having experiences of interacting with doctors on social media, and filling the questionnaire sincerely, etc. Service providers whose answers met our requirements received a token of appreciation, whereas providers who failed our requirements did not receive the token. Participants also provided informed consent before they filled the questionnaires. After 2 weeks, we obtained a total of 435 responses from Chinese social media consumers who had experienced interactions with doctors on social media.

Because we used Web-based data, several actions were taken to ensure the validity of dataset [44]. To identify the applicable respondents, we set screening questions to check whether the respondents were consumers who interacted with doctors on social media, such as whether participants followed doctors on social media, whether they replied to doctors' posts on social media, and whether they forwarded doctors' posts on social media. To avoid responses from experienced survey takers or ones with less attention, we discarded 39 cases that took less than 5 min and checked the cases with missing values or similar values for all questions. To address cheating issues, we did not use the data from respondents who had not correctly responded 
to the set reverse-coded questions. Thus, we were left with 352 complete and valid responses. In this sample, most of the respondents were in the age group of 25-30 years, were females, possessed a college degree, and were familiar with using social media. This is reasonably consistent with the report of China Internet Network Information Center on demographics of Chinese social media consumers [45]. The specific demographic information of our final sample is summarized in Table 1.

\section{Measurement Instrument}

To validate our research model, we used the survey method in this study. The survey instrument was developed by adapting previously validated scales to the context of our study. Items for affective and instrumental interaction were adapted from Ben-Sira who had studied relevant variables [28]. Items for DK and health behaviors were adapted from the Activity Question Scale, Nutrition Knowledge Scale, and Health Lifestyle Behavior Scale [46]. Items for SE were adapted from the General Self-Efficacy Scale [47] and those for OE were from the Anderson et al study, which had covered OE in other context [48]. A total of 42 items that contain screening questions and demographic questions were presented in the questionnaire. All items were measured on a 5-point Likert scale with anchors ranging from strongly disagree to strongly agree.

As the survey instrument was originally developed in English, we used the back translation method to translate it into Chinese. The English instrument was first translated into Chinese by one of the bilingual authors, TW, whose native language was Chinese. Next, another bilingual author, DZ, back translated the Chinese version into English. The 2 authors then compared the 2 English versions to check for inconsistency, if any. A pretest was conducted on the developed survey instrument by interviewing 8 experts in the area of information systems, medical informatics, and health management and 17 users of social media. We further revised the questionnaire based on the comments and suggestions received. The survey instrument is presented in Multimedia Appendix 1.

\section{Statistical Analysis}

This study employed structural equation modeling using partial least square (PLS) analysis. As the second-generation multivariate causal analysis method, PLS can be applied to complex structural equation models and is less restrictive on sample size than other methods [49,50]. Meanwhile, PLS is suitable for exploratory studies as it aims at theory building rather than theory testing. The analysis was conducted by using SmartPLS 2.0.3M of SmartPLS GmbH in Germany [51].

We analyzed the reliability and validity of measurement instruments using confirmatory factor analysis. As shown in Table 2, all Cronbach alpha and composite reliabilities are above 0.6 , thus demonstrating reliability for all constructs [52]. The value of average variance extracted (AVE) of each construct is above 0.5 and items' loadings are above 0.7 , thus demonstrating good convergent validity [52]. On the basis of the results shown in Table 3, the square roots of the AVEs are all greater than the interconstruct correlations, thus demonstrating discriminant validity [53]. Hence, we conclude that the quality of the measurement model is adequate for testing hypothesized relationships. 
Table 1. Demographic information.

\begin{tabular}{|c|c|}
\hline Characteristics & $\mathrm{n}(\%)$ \\
\hline \multicolumn{2}{|l|}{ Age in years } \\
\hline$<25$ & $122(34.7)$ \\
\hline $25-30$ & $150(42.6)$ \\
\hline$>30$ & $80(22.7)$ \\
\hline \multicolumn{2}{|l|}{ Gender } \\
\hline Male & $153(43.5)$ \\
\hline Female & $199(56.5)$ \\
\hline \multicolumn{2}{|l|}{ Education } \\
\hline High school & $35(9.9)$ \\
\hline College & $304(86.4)$ \\
\hline Master's degree and above & $13(3.7)$ \\
\hline \multicolumn{2}{|c|}{ Duration of using social media within a day } \\
\hline$<1$ hour/day & $164(46.6)$ \\
\hline $1-3$ hours/day & $128(36.4)$ \\
\hline$>3$ hours/day & $60(17)$ \\
\hline \multicolumn{2}{|c|}{ Experiences of using social media } \\
\hline$<1$ year & $29(8.2)$ \\
\hline $1-5$ years & $201(57.1)$ \\
\hline More than 5 years & $122(34.7)$ \\
\hline
\end{tabular}

We also examined the possibility of common method bias in our study. First, we looked into the correlational coefficients among variables in Table 3 and found that none of the pairs had a very high correlation ( $r>90)$ [53]. Second, we conducted Harman single-factor test using principle component analysis in SPSS 18.0 of International Business Machines Corporation in United Stated. Ten factors were extracted and the first factor in the unrotated solution explained $31 \%$, which is less than $50 \%$ [54]. Third, we employed the marker variable technique to test common method bias [55]. We used perceived organizational support as the marker variable. The average correlation among perceived organizational support and those of the principle constructs is $r=.198$. Therefore, common method bias may not be an issue in our study. 
Table 2. Construct reliability and convergent validity.

\begin{tabular}{|c|c|c|c|c|}
\hline Construct and items & Factor loadings & Composite reliability & Average variance extracted & Cronbach alpha \\
\hline \multicolumn{5}{|c|}{ Instrumental interaction (INI) } \\
\hline INI1 & 0.8021 & 0.8125 & 0.5912 & .6547 \\
\hline INI2 & 0.7388 & & & \\
\hline INI3 & 0.7644 & & & \\
\hline \multicolumn{5}{|c|}{ Affective interaction (AI) } \\
\hline AI1 & 0.7639 & 0.8051 & 0.5793 & .6369 \\
\hline AI2 & 0.7704 & & & \\
\hline AI3 & 0.7489 & & & \\
\hline \multicolumn{5}{|c|}{ Declarative knowledge (DK) } \\
\hline DK1 & 0.7566 & 0.8564 & 0.5444 & .7912 \\
\hline DK2 & 0.769 & & & \\
\hline DK3 & 0.7582 & & & \\
\hline DK4 & 0.7022 & & & \\
\hline DK5 & 0.7002 & & & \\
\hline \multicolumn{5}{|l|}{ Self-efficacy (SE) } \\
\hline SE1 & 0.7798 & 0.8876 & 0.6124 & .8419 \\
\hline SE2 & 0.7624 & & & \\
\hline SE3 & 0.7873 & & & \\
\hline SE4 & 0.7869 & & & \\
\hline SE5 & 0.796 & & & \\
\hline \multicolumn{5}{|c|}{ Outcome expectancy (OE) } \\
\hline OE1 & 0.7635 & 0.8342 & 0.6239 & .6983 \\
\hline OE2 & 0.8345 & & & \\
\hline OE3 & 0.7697 & & & \\
\hline \multicolumn{5}{|c|}{ Health behaviors (HB) } \\
\hline HB1 & 0.8094 & 0.9021 & 0.5688 & .8737 \\
\hline $\mathrm{HB} 2$ & 0.7335 & & & \\
\hline HB3 & 0.7244 & & & \\
\hline HB4 & 0.7611 & & & \\
\hline HB5 & 0.731 & & & \\
\hline HB6 & 0.7916 & & & \\
\hline HB7 & 0.7232 & & & \\
\hline
\end{tabular}

Table 3. Discriminant validity. The square roots of average variance extracted (AVEs) are in italics.

\begin{tabular}{|c|c|c|c|c|c|c|}
\hline Constructs & $\begin{array}{l}\text { Instrumental } \\
\text { interaction }\end{array}$ & Affective interaction & $\begin{array}{l}\text { Declarative } \\
\text { knowledge }\end{array}$ & Self-efficacy & $\begin{array}{l}\text { Outcome } \\
\text { expectancy }\end{array}$ & Health behaviors \\
\hline Instrumental interaction & 0.7681 & & & & & \\
\hline Affective interaction & 0.558 & 0.7611 & & & & \\
\hline Declarative knowledge & 0.4757 & 0.4346 & 0.7378 & & & \\
\hline Self-efficacy & 0.4204 & 0.4217 & 0.2574 & 0.7826 & & \\
\hline Outcome expectancy & 0.5193 & 0.4653 & 0.5408 & 0.3536 & 0.7899 & \\
\hline Health behaviors & 0.4463 & 0.403 & 0.3924 & 0.39 & 0.3597 & 0.7542 \\
\hline
\end{tabular}




\section{Results}

\section{Analysis Results of Hypothesized Model}

PLS with bootstrapping procedure was used to test the hypothesized model. Estimates derived from the PLS analysis were used to test the research hypotheses. The results of the analysis are summarized in Figure 2. The results revealed that DK, SE, and OE significantly influenced consumers' health behaviors. The significant effect of these 3 constructs demonstrated the explanatory power of social exchange theory. Therefore, H1, H2, and H3 were all supported. With regard to the impact of the interaction between doctors and consumers, the results showed that both types of doctor-consumer interactions significantly affected consumers' DK, SE, and OE. These results manifested that the interaction between doctors and consumers on social media could increase consumers' DK of health, enforce their SE of doing healthy lifestyle behaviors, and lead to positive OE of doing healthy lifestyle behaviors. Therefore, H4a, H4b, H5a, H5b, H6a, and H6b were all supported.

\section{Mediation Analysis of Declarative Knowledge, Self-Efficacy, and Outcome Expectancy}

To test the mediation role of DK, SE, and OE, we adopted the bootstrapping technique [56,57]. Compared with traditional methods such as the Baron and Kenny [58] method and the Sobel [59] method, the bootstrapping method can test the indirect effect of independent variables on dependent variables directly and does not require the normal distribution of mediation effect [60]. In this study, the $95 \%$ confidence interval of the indirect effects was obtained with 5000 bootstrap resamples. By using the SmartPLS 2.0 M3 [51], we summarize the mediation analysis results in Table 4 . According to the results, the indirect effects of instrumental interaction and affective interaction on health behaviors were significant. Therefore, DK, SE, and OE significantly mediated the relationship between doctor-consumer interaction and health interaction. Meanwhile, based on the significance of direct effect, the effect of instrumental interaction on health behaviors was partially mediated by that of DK, SE, and OE, whereas the relationship between affective interaction and health behaviors was fully mediated by that of DK, SE, and OE. 
Figure 2. Analysis results of structural model.

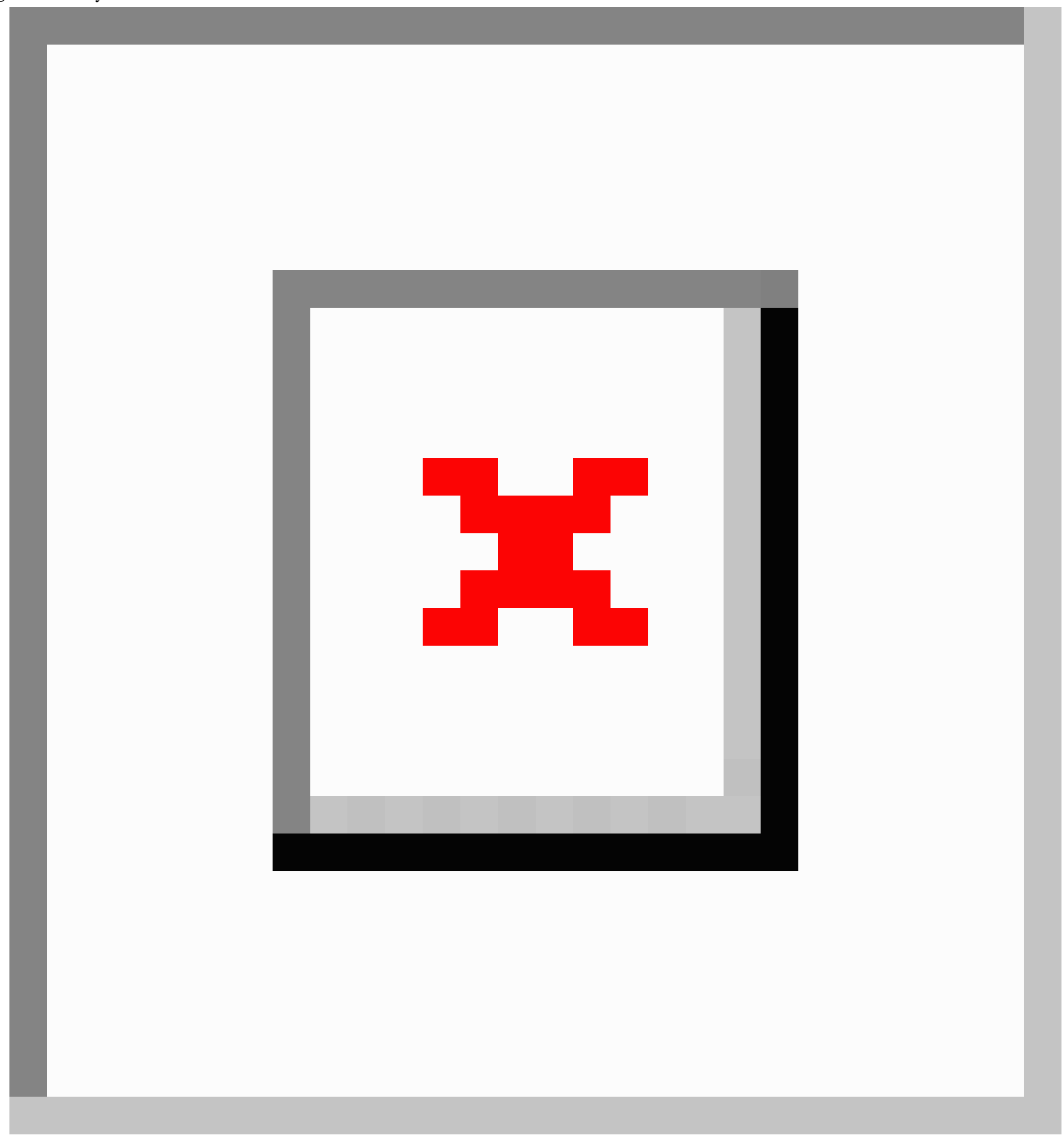


Table 4. Mediation analysis using bootstrapping method.

\begin{tabular}{|c|c|c|c|c|c|c|c|c|c|}
\hline \multirow{2}{*}{$\begin{array}{l}\text { Independent } \\
\text { variable }\end{array}$} & \multirow{2}{*}{$\begin{array}{l}\text { Mediating } \\
\text { variable }\end{array}$} & \multirow{2}{*}{$\begin{array}{l}\text { Dependent } \\
\text { variable }\end{array}$} & \multicolumn{3}{|c|}{ Indirect effect } & \multicolumn{3}{|c|}{ Direct effect } & \multirow[t]{2}{*}{ Mediation proportion } \\
\hline & & & $2.5 \% \mathrm{CI}$ & $97.5 \% \mathrm{CI}$ & Effect value & $2.5 \% \mathrm{CI}$ & $97.5 \% \mathrm{CI}$ & Effect value & \\
\hline $\mathrm{INI}^{\mathrm{a}}$ & $\mathrm{DK}^{\mathrm{b}}$ & $\mathrm{HB}^{\mathrm{c}}$ & 0.0275 & 0.1311 & 0.0793 & 0.0744 & 0.3096 & 0.1920 & Partial mediation \\
\hline INI & $S E^{d}$ & $\mathrm{HB}$ & 0.0186 & 0.1084 & 0.0635 & 0.0744 & 0.3096 & 0.1920 & Partial mediation \\
\hline INI & $\mathrm{OE}^{\mathrm{e}}$ & $\mathrm{HB}$ & 0.0159 & 0.1198 & 0.0679 & 0.0744 & 0.3096 & 0.1920 & Partial mediation \\
\hline $\mathrm{AI}^{\mathrm{f}}$ & DK & $\mathrm{HB}$ & 0.0180 & 0.0972 & 0.0576 & -0.0050 & 0.2437 & 0.1220 & Full mediation \\
\hline AI & SE & $\mathrm{HB}$ & 0.0181 & 0.1103 & 0.0642 & -0.0050 & 0.2437 & 0.1220 & Full mediation \\
\hline AI & $\mathrm{OE}$ & $\mathrm{HB}$ & 0.0057 & 0.0861 & 0.0459 & -0.0050 & 0.2437 & 0.1220 & Full mediation \\
\hline
\end{tabular}

${ }^{\mathrm{a}}$ INI: instrumental interaction.

${ }^{\mathrm{b}} \mathrm{DK}$ : declarative knowledge.

${ }^{\mathrm{c}} \mathrm{HB}$ : health behaviors.

${ }^{\mathrm{d}} \mathrm{SE}$ : self-efficacy.

${ }^{\mathrm{e}} \mathrm{OE}$ : outcome expectancy.

${ }^{\mathrm{f}} \mathrm{AI}$ : affective interaction.

\section{Discussion}

\section{Principal Findings}

In this paper, we studied the effect of doctor-consumer interaction on social media on consumers' health behaviors empirically. On the basis of professional-client interaction theory, we divided doctor-consumer interaction into instrumental interaction and affective interaction and conceptualized them in the social media context. In the meantime, depending on social cognitive theory, we proposed 3 variables that mediate the relationship between doctor-consumer interaction on social media and consumers' health behaviors: DK, SE, and OE. To test our hypotheses, we established a research model by integrating the above theories and developing corresponding measurement instruments. By using the survey method, we collected data from consumers who had the experience of interacting with doctors in China. By analyzing the data, we found that all our hypothetical relationships were supported. Therefore, we can conclude that interacting with doctors on social media can improve consumers' health behaviors.

Furthermore, we also looked into the mediation effect of the 3 proposed mediators. By using the advanced bootstrapping method, we discovered that the effect of instrumental interaction on health behaviors was partially mediated by DK, SE, and OE, whereas the effect of affective interaction on health behaviors was fully mediated by the above mediators. Therefore, the 3 mediators are adequate to explain the process from instrumental interaction to health behaviors, whereas more potential mediators are needed to be explored for the effect of affective interaction on health behaviors.

\section{Implications}

This study brings a few interesting contributions to theory and practice. From the theoretical perspective, we extend professional-client interaction theory into the social media context by conceptualizing doctor-consumer interaction in social media and dividing it into instrumental and affective interaction. Our empirical study confirms the effectiveness of this extension.
Meanwhile, the 2 types of interaction provide a deep insight into understanding the role of doctor-consumer interaction.

Second, we integrate professional-client interaction theory and social cognitive theory in this study. Professional-client interaction theory helps us understand doctor-consumer interaction in the social media context, whereas social cognitive theory points out the underlying working mechanisms of the effect of doctor-consumer interaction. By integrating these 2 theories, we describe a full map of the role of doctor-consumer interaction.

Third, we propose and test 3 working mechanisms of doctor-consumer interaction. DK, SE, and $\mathrm{OE}$ are proposed as the working mechanisms based on social cognitive theory. Compared with previous literature, we first consider the role of DK in health behaviors and test all the 3 factors in the social media context. Especially, our mediation analysis uncovered that these 3 mediators fully mediated the effect of affective interaction and partially mediated the effect of instrumental interaction.

From a practical perspective, this study suggests that doctor-consumer interaction can be considered as a natural intervention to change consumers' health behaviors and then their health status. Therefore, compared with traditional offline health education and promotion activities, health care providers and health educators could pay attention to doctors' activities on social media. Doctor-consumer interaction guidelines should be developed. Meanwhile, consumers should be encouraged to interact with doctors on social media.

Second, both instrumental and affective interaction could be considered in doctor-consumer interaction on social media. Compared with interaction in the offline context, the role of affective interaction should be highlighted in the social media context. For example, besides providing professional suggestions to consumers, doctors should show their interests on consumers' health problems and give them enough chances to express their anxiety and confusion. 
Finally, the proposed working mechanisms can help evaluate the effectiveness of doctor-consumer interaction. Health care providers and health educators can even refer our measurement scales to check the effects of their interaction with consumers on social media.

\section{Limitations and Future Work}

The results of this study should be interpreted in the light of its limitations. First of all, we have indeed identified several working mechanisms of doctor-consumer interaction; however, our mediation analysis indicates that more working mechanisms await exploration, especially for the instrumental effect. Future studies can consider other mediators and other theoretical perspectives to improve the validity of our research model. Moreover, interaction among consumers about health problems may also influence consumers' attitude toward health behaviors. Future studies can include both doctor-consumer interaction and consumer-consumer interaction.

Second, the generalizability may be restricted as our sample is restricted to Chinese consumers rather than people from other countries. In China, the two most popular social media platforms are WeChat and Weibo [45], but in other countries, other social media platforms such as Facebook or Twitter are more dominant. Differences between WeChat or Weibo and social media platforms in other countries exist. For example, Twitter is a global microblogging service provider and keeps itself simple, whereas Weibo focuses on China and adds many features in its platform [61]. These differences may make consumers in these 2 platforms behave differently. Future studies may conduct cross-country comparisons to better generalize the results of this study.

Third, our study is a cross-sectional one in which constructs were measured at the same point of time. However, as consumer behavior and social media are both dynamic, the results may change with the passage of time. Therefore, the cross-sectional design may not reflect the dynamics of social media usage. Meanwhile, the time sequence of independent variables, mediators, and dependent variables could not be revealed in a cross-sectional survey. A longitudinal study that collects the data of different variables at different times may help address this issue.

Finally, although the explained variance of health behaviors in our structural model is acceptable, some unexplained variance remains and other relevant factors should be explored. In this study, we applied the social cognitive theory and only considered the personal factors including DK, SE, and OE to explain health behaviors; other situational and environmental factors should be included in future studies. Moreover, other theories such as the health belief model could be applied to understand health behaviors [62].

\section{Conclusions}

This paper contributes to the literature on doctor-patient communication by investigating doctor-consumer interaction on social media. Our study demonstrated the important role of doctor-consumer interaction on social media for consumers' health behaviors. This result not only implies that social media could be feasible channels to promote consumers' health behaviors but also reveals that doctors could consider engaging in using social media to interact with consumers for health purposes. The significant mediating role of DK, SE, and OE consists of the working mechanisms of doctor-consumer interaction on social media. Theoretical and practical implications for leveraging social media to promote health behaviors are provided.

\section{Acknowledgments}

This work was partially supported by grants from the National Natural Science Foundation of China (No 71671073 and No 71673098) and China Postdoctoral Science Foundation (No 2017M622468). The authors would like to thank Prof Bernadette Mazurek Melnyk for her generous sharing of the scales of health behaviors and others.

\section{Conflicts of Interest}

None declared.

\section{Multimedia Appendix 1}

Measurement instruments.

[PDF File (Adobe PDF File), 34KB-Multimedia Appendix 1]

\section{References}

1. Statista. 2017. Percentage of U.S. population with a social media profile from 2008 to 2017 URL: $\underline{\text { https://www.statista.com/ }}$ statistics/273476/percentage-of-us-population-with-a-social-network-profile/ [accessed 2017-09-16] [WebCite Cache ID 6tVubjfGM]

2. Statista. 2016. Number of social network users in China from 2014 to 2021 (in millions) URL: https://www.statista.com/ statistics/277586/number-of-social-network-users-in-china/ [accessed 2017-09-01] [WebCite Cache ID 6t95CYXu4]

3. SMA. 2017. Social media \& Health care by the numbers URL: https://sma.org/social-media-healthcare-by-the-numbers/ [accessed 2017-09-01] [WebCite Cache ID 6t9k0IKKW]

4. Beckersspine. 2016. 10 things to know about social media in healthcare: Who's using it? Does it make a difference? URL: http://www.beckersspine.com/orthopedic-spine-practices-improving-profits/item/ 
29986-10-things-to-know-about-social-media-in-healthcare-who-s-using-it-does-it-make-a-difference.html [accessed 2017-09-01] [WebCite Cache ID 6t93pwHY5]

5. Ventola CL. Social media and health care professionals: benefits, risks, and best practices. P T 2014 Jul;39(7):491-520 [FREE Full text] [Medline: 25083128]

6. Suler J. The online disinhibition effect. Cyberpsychol Behav 2004 Jun;7(3):321-326. [doi: 10.1089/1094931041291295] [Medline: 15257832]

7. Househ M, Borycki E, Kushniruk A. Empowering patients through social media: the benefits and challenges. Health Informatics J 2014 Mar;20(1):50-58. [doi: 10.1177/1460458213476969] [Medline: 24550564]

8. Kaplan AM, Haenlein M. Users of the world, unite! The challenges and opportunities of social media. Bus Horiz 2010 Jan;53(1):59-68. [doi: 10.1016/j.bushor.2009.09.003]

9. Smailhodzic E, Hooijsma W, Boonstra A, Langley DJ. Social media use in healthcare: a systematic review of effects on patients and on their relationship with healthcare professionals. BMC Health Serv Res 2016 Aug 26;16:442 [FREE Full text] [doi: 10.1186/s12913-016-1691-0] [Medline: 27562728]

10. Merolli M, Gray K, Martin-Sanchez F. Health outcomes and related effects of using social media in chronic disease management: a literature review and analysis of affordances. J Biomed Inform 2013 Dec;46(6):957-969 [FREE Full text] [doi: 10.1016/j.jbi.2013.04.010] [Medline: 23702104]

11. kznhealth. 1999. Healthy living : what is a healthy lifestyle? URL: http://www.kznhealth.gov.za/healthyliving.pdf [accessed 2017-09-01] [WebCite Cache ID 6t9jwD05g]

12. Knowler WC, Barrett-Connor E, Fowler SE, Hamman RF, Lachin JM, Walker EA, Diabetes Prevention Program Research Group. Reduction in the incidence of type 2 diabetes with lifestyle intervention or metformin. N Engl J Med 2002 Feb 7;346(6):393-403 [FREE Full text] [doi: 10.1056/NEJMoa012512] [Medline: 11832527 ]

13. Appel LJ, Champagne CM, Harsha DW, Cooper LS, Obarzanek E, Elmer PJ, Writing Group of the PREMIER Collaborative Research Group. Effects of comprehensive lifestyle modification on blood pressure control: main results of the PREMIER clinical trial. J Am Med Assoc 2003;289(16):2083-2093. [doi: 10.1001/jama.289.16.2083] [Medline: 12709466]

14. Chiuve SE, Rexrode KM, Spiegelman D, Logroscino G, Manson JE, Rimm EB. Primary prevention of stroke by healthy lifestyle. Circulation 2008 Aug 26;118(9):947-954 [FREE Full text] [doi: 10.1161/CIRCULATIONAHA.108.781062] [Medline: $\underline{18697819}$ ]

15. Pope SK, Shue VM, Beck C. Will a healthy lifestyle help prevent Alzheimer's disease? Annu Rev Public Health 2003;24:111-132. [doi: 10.1146/annurev.publhealth.24.100901.141015] [Medline: 12415146]

16. Ford ES, Bergmann MM, Kröger J, Schienkiewitz A, Weikert C, Boeing H. Healthy living is the best revenge: findings from the European Prospective Investigation Into Cancer and Nutrition-Potsdam study. Arch Intern Med 2009 Aug 10;169(15):1355-1362. [doi: 10.1001/archinternmed.2009.237] [Medline: 19667296]

17. Kushner RF, Choi SW. Prevalence of unhealthy lifestyle patterns among overweight and obese adults. Obesity (Silver Spring) 2010 Jun;18(6):1160-1167 [FREE Full text] [doi: 10.1038/oby.2009.376] [Medline: 19875995]

18. Bonnet F, Irving K, Terra J, Nony P, Berthezène F, Moulin P. Anxiety and depression are associated with unhealthy lifestyle in patients at risk of cardiovascular disease. Atherosclerosis 2005 Feb;178(2):339-344. [doi: 10.1016/j.atherosclerosis.2004.08.035] [Medline: 15694943]

19. Wald A, Muennig PA, O'Connell KA, Garber CE. Associations between healthy lifestyle behaviors and academic performance in U.S. undergraduates: a secondary analysis of the American College Health Association's National College Health Assessment II. Am J Health Promot 2014;28(5):298-305. [doi: 10.4278/ajhp.120518-QUAN-265] [Medline: 23941106]

20. Marmot M, Friel S, Bell R, Houweling TA, Taylor S, Commission on Social Determinants of Health. Closing the gap in a generation: health equity through action on the social determinants of health. Lancet 2008 Nov 8;372(9650):1661-1669. [doi: 10.1016/S0140-6736(08)61690-6] [Medline: 18994664]

21. US Department of Health and Human Services. Healthypeople. 2017. Healthy People 2020 URL: https://www. healthypeople.gov/2020/About-Healthy-People [accessed 2017-09-16] [WebCite Cache ID 6tVulhzJX]

22. State Concil of China. Gov.cn. 2016. Healthy China 2030 Program URL: http://www.gov.cn/zhengce/2016-10/25/ content 5124174.htm [accessed 2017-09-01] [WebCite Cache ID 6t94maAsb]

23. Maher CA, Lewis LK, Ferrar K, Marshall S, De Bourdeaudhuij I, Vandelanotte C. Are health behavior change interventions that use online social networks effective? A systematic review. J Med Internet Res 2014;16(2):e40 [FREE Full text] [doi: 10.2196/jmir.2952] [Medline: 24550083]

24. Cavallo DN, Tate DF, Ries AV, Brown JD, DeVellis RF, Ammerman AS. A social media-based physical activity intervention: a randomized controlled trial. Am J Prev Med 2012 Nov;43(5):527-532 [FREE Full text] [doi: 10.1016/j.amepre.2012.07.019] [Medline: 23079176]

25. Williams G, Hamm MP, Shulhan J, Vandermeer B, Hartling L. Social media interventions for diet and exercise behaviours: a systematic review and meta-analysis of randomised controlled trials. BMJ Open 2014;4(2):e003926 [FREE Full text] [doi: 10.1136/bmjopen-2013-003926] [Medline: 24525388]

26. Hawn C. Take two aspirin and tweet me in the morning: how Twitter, Facebook, and other social media are reshaping health care. Health Aff (Millwood) 2009;28(2):361-368 [FREE Full text] [doi: 10.1377/hlthaff.28.2.361] [Medline: 19275991] 
27. Ben-Sira Z. The function of the professional's affective behavior in client satisfaction: a revised approach to social interaction theory. J Health Soc Behav 1976 Mar;17(1):3-11. [Medline: 1270783]

28. Ben-Sira Z. Affective and instrumental components in the physician-patient relationship: an additional dimension of interaction theory. J Health Soc Behav 1980 Jun;21(2):170-180. [Medline: 7391531]

29. Hong W, Chan FK, Thong JY, Chasalow LC, Dhillon G. A framework and guidelines for context-specific theorizing in information systems research. Inf Syst Res 2014 Mar;25(1):111-136. [doi: 10.1287/isre.2013.0501]

30. Bandura A. Social Foundations of Thought and Action: A Social Cognitive Perspective. Englewood Cliffs, NJ: Princeton-Hall; 1986.

31. Compeau D, Higgins CA, Huff S. Social cognitive theory and individual reactions to computing technology: a longitudinal study. MIS Q 1999 Jun;23(2):145-158. [doi: 10.2307/249749]

32. Glanz K, Rimer B, Viswanath K. Health Behavior and Health Education: Theory, Research, and Practice. San Francisco, CA: John Wiley \& Sons; 2008.

33. Anderson JR. Acquisition of cognitive skill. Psychol Rev 1982;89(4):369-406. [doi: 10.1037/0033-295X.89.4.369]

34. Bruns $\varnothing$ K, Scholderer J, Grunert KG. Closing the gap between values and behavior-a means-end theory of lifestyle. J Bus Res 2004 Jun;57(6):665-670. [doi: 10.1016/S0148-2963(02)00310-7]

35. Bandurat A. Self-regulation of motivationaction through internal standardsgoal systems. In: Goal Concepts in Personality and Social Psychology. Erlbaum: Hillsdale, NJ; 1989:19-85.

36. Bandura A. Self-Efficacy: The Exercise of Control. New York, NY: Freeman; 1997.

37. Bandura A. Health promotion from the perspective of social cognitive theory. Psychol Health 1998 Jul;13(4):623-649. [doi: 10.1080/08870449808407422]

38. Meglino BM, Korsgaard A. Considering rational self-interest as a disposition: organizational implications of other orientation. J Appl Psychol 2004 Dec;89(6):946-959. [doi: 10.1037/0021-9010.89.6.946] [Medline: 15584834]

39. Alavi M, Leidner DE. Knowledge management and knowledge management systems: conceptual foundations and research issues. MIS Q 2001 Mar;25(1):107. [doi: 10.2307/3250961]

40. Roberts CA, Aruguete MS. Task and socioemotional behaviors of physicians: a test of reciprocity and social interaction theories in analogue physician-patient encounters. Soc Sci Med 2000 Feb;50(3):309-315. [doi: 10.1016/S0277-9536(99)00245-2]

41. Bandura A. Self-efficacy mechanism in human agency. Am Psychol 1982;37(2):122-147. [doi: 10.1037/0003-066X.37.2.122]

42. Bandura A. Influence of models' reinforcement contingencies on the acquisition of imitative responses. J Pers Soc Psychol 1965 Jun;1:589-595. [Medline: 14300234]

43. Compeau DR, Higgins CA. Application of social cognitive theory to training for computer skills. Inf Syst Res 1995 Jun;6(2):118-143. [doi: $10.1287 /$ isre.6.2.118]

44. Lowry PB, D’Arcy J, Hammer B, Moody GD. "Cargo Cult" science in traditional organization and information systems survey research: a case for using nontraditional methods of data collection, including Mechanical Turk and online panels. J Strateg Inform Syst 2016 Oct;25(3):232-240. [doi: 10.1016/j.jsis.2016.06.002]

45. China Internet Nework Information Center. Cnnic. 2017. 39th statistical report on Internet development in China URL: https://cnnic.com.cn/IDR/ReportDownloads/201706/P020170608523740585924.pdf[WebCite Cache ID 6t9105igO]

46. Kelly SA, Melnyk BM, Jacobson DL, O'Haver JA. Correlates among healthy lifestyle cognitive beliefs, healthy lifestyle choices, social support, and healthy behaviors in adolescents: implications for behavioral change strategies and future research. J Pediatr Health Care 2011;25(4):216-223. [doi: 10.1016/j.pedhc.2010.03.002] [Medline: 21700136]

47. Chen G, Gully SM, Eden D. Validation of a New General Self-Efficacy Scale. Organ Res Methods 2001 Jan;4(1):62-83. [doi: $10.1177 / 109442810141004]$

48. Anderson ES, Wojcik JR, Winett RA, Williams DM. Social-cognitive determinants of physical activity: the influence of social support, self-efficacy, outcome expectations, and self-regulation among participants in a church-based health promotion study. Health Psychol 2006 Jul;25(4):510-520. [doi: 10.1037/0278-6133.25.4.510] [Medline: 16846326]

49. Download.cicdata. 2016. China Social Media Impact Report URL: http://download.cicdata.com/upload/Kantar/ EN-Kantar Social Media Impact Report 2017.pdf [accessed 2017-09-01] [WebCite Cache ID 6t9ksqapK]

50. Urbach N, Ahlemann F. Structural equation modeling in information systems research using partial least squares. J Inform Technology Theory Appl 2010;11(2):5-40.

51. Smartpls. 2005. SmartPLS 2 URL: http://www.smartpls.de[WebCite Cache ID 6x8zWPspb]

52. Nunnally J, Bernstein I. Psychometric Theory. New York: McGraw-Hill; 1967.

53. Fornell C, Larcker DF. Evaluating structural equation models with unobservable variables and measurement error. J Mark Res 1981 Feb;18(1):39. [doi: 10.2307/3151312]

54. Bagozzi RP, Yi Y, Phillips LW. Assessing construct validity in organizational research. Adm Sci Q 1991 Sep;36(3):421. [doi: $10.2307 / 2393203$ ]

55. Lindell MK, Whitney DJ. Accounting for common method variance in cross-sectional research designs. J Appl Psychol 2001;86(1):114-121. [doi: 10.1037/0021-9010.86.1.114]

56. Zhao X, Lynch JG, Chen Q. Reconsidering Baron and Kenny: myths and truths about mediation analysis. J Consum Res 2010 Aug 01;37(2):197-206. [doi: 10.1086/651257] 
57. Preacher KJ, Hayes AF. Asymptotic and resampling strategies for assessing and comparing indirect effects in multiple mediator models. Behav Res Methods 2008 Aug;40(3):879-891. [doi: 10.3758/BRM.40.3.879]

58. Baron R, Kenny D. The moderator-mediator variable distinction in social psychological research: conceptual, strategic, and statistical considerations. J Pers Soc Psychol 1986 Dec;51(6):1173-1182 [FREE Full text] [doi: 10.1037/0022-3514.51.6.1173] [Medline: 3806354]

59. Sobel M. Asymptotic confidence intervals for indirect effects in structural equation models. Sociol Methodol 1982;13:290-312. [doi: 10.2307/270723]

60. MacKinnon DP, Lockwood CM, Hoffman JM, West SG, Sheets V. A comparison of methods to test mediation and other intervening variable effects. Psychol Methods 2002 Mar;7(1):83-104 [FREE Full text] [Medline: 11928892]

61. Gao Q, Abel F, Houben G, Yu Y. A comparative study of users? Microblogging behavior on Sina Weibo and Twitter. : Springer; 2012 Presented at: International Conference on User Modeling, Adaptation, and Personalization; July 16-20; Montreal, QC, Canada.

62. Janz NK, Becker MH. The Health Belief model: a decade later. Health Educ Q 1984;11(1):1-47. [doi: 10.1177/109019818401100101] [Medline: 6392204]
Abbreviations
AI: affective interaction
AVE: average variance extracted
DK: declarative knowledge
HB: health behaviors
INI: instrumental interaction
OE: outcome expectancy
SE: self-efficacy

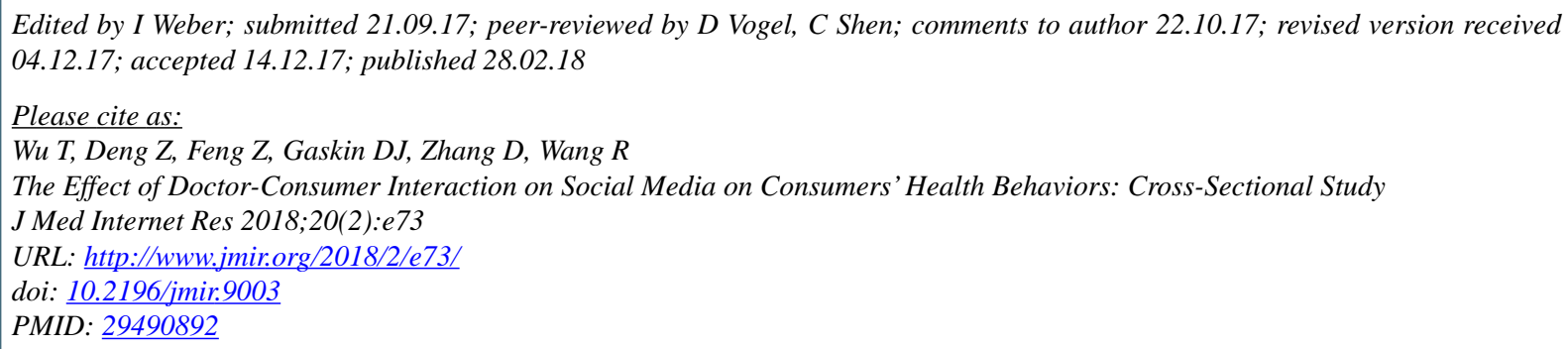

(C) Tailai Wu, Zhaohua Deng, Zhanchun Feng, Darrell J Gaskin, Donglan Zhang, Ruoxi Wang. Originally published in the Journal of Medical Internet Research (http://www.jmir.org), 28.02.2018. This is an open-access article distributed under the terms of the Creative Commons Attribution License (https://creativecommons.org/licenses/by/4.0/), which permits unrestricted use, distribution, and reproduction in any medium, provided the original work, first published in the Journal of Medical Internet Research, is properly cited. The complete bibliographic information, a link to the original publication on http://www.jmir.org/, as well as this copyright and license information must be included. 